\title{
Human Milk and Preterm Infant Brain Development
}

\author{
Mandy Brown Belfort ${ }^{1,2}$
}

$\mathbf{E}$ ARLY INFANCY IS A CRITICAL PERIOD for brain development (Fig. 1). ${ }^{1,2}$ Early life exposures, including nutrition, can have lasting effects on the structure and function of the developing brain. The preterm infant is particularly vulnerable to effects of undernutrition during the neonatal intensive care unit (NICU) hospitalization. Breast milk provides nutrients to support rapid growth and development, as well as non-nutrient bioactive factors (e.g., antibodies, hormones, enzymes, and oligosaccharides) that prevent infection and reduce inflammation, ${ }^{3}$ both of which contribute to brain injury and altered development. Breast milk can also serve as a marker for maternal care, because breastfeeding is associated with more time spent in emotional care, greater maternal sensitivity, stronger infant attachment security, and more mother-infant interaction during feeding. ${ }^{4-7}$ Quality mother-infant interaction is associated with better neurocognitive outcome. ${ }^{7}$

Both observational and experimental studies have studied the effects of breastfeeding on infant brain development and neurodevelopmental outcomes among healthy populations. An observational cohort study (Project Viva; $N=1,312$ mothers and children) found a clear linear association between breastfeeding duration and verbal IQ at 7 years of age (Fig. 2). ${ }^{8}$ For each additional month of breastfeeding (any amount), verbal IQ score was 0.4 -points higher at 7 years.
The effects were greater in magnitude for exclusive breastfeeding; verbal IQ score was 0.8-points higher at 7 years for each additional month of exclusive breastfeeding to 6 months. A separate observational study comparing brain structure in formula-fed and breastfed children aged 10 months to 4 years demonstrated increased white matter development in frontal and association brain regions in breastfed infants. ${ }^{9}$ These differences in white matter structure corresponded to improved cognitive and behavioral performance in breastfed children, supporting the association of breastfeeding with better cognitive development. Findings from the PROmotion of Breastfeeding Intervention Trial (PROBIT), a randomized cluster trial that enrolled 17,046 mother-infant pairs in 31 maternity hospitals, support a causal effect of breastfeeding on IQ; prolonged and exclusive breastfeeding was associated with a 7.5-point increase in verbal IQ score at age 6.5 years compared with controls. ${ }^{10}$

Studies demonstrating the benefits of breastfeeding may not be generalizable to preterm infants, who are more nutritionally vulnerable than full-term infants. Administering human milk to preterm infants is associated with short-term clinical benefits, such as faster feeding advancement and reduced risk of necrotizing enterocolitis and late-onset sepsis. ${ }^{1-13}$ Human
FIG. 1. Growth and development of the preterm human brain.

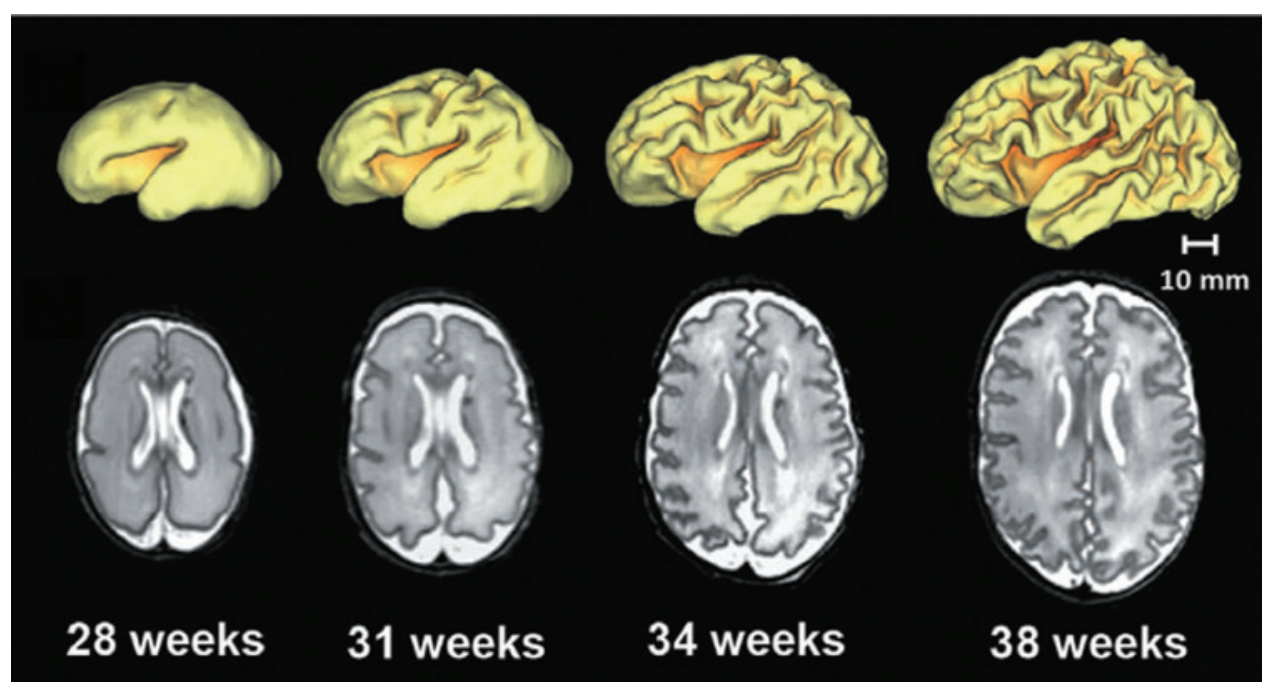

\footnotetext{
${ }^{1}$ Neonatologist, Brigham and Women's Hospital, Boston, Massachusetts.

${ }^{2}$ Assistant Professor of Pediatrics, Harvard Medical School, Boston, Massachusetts.
} 


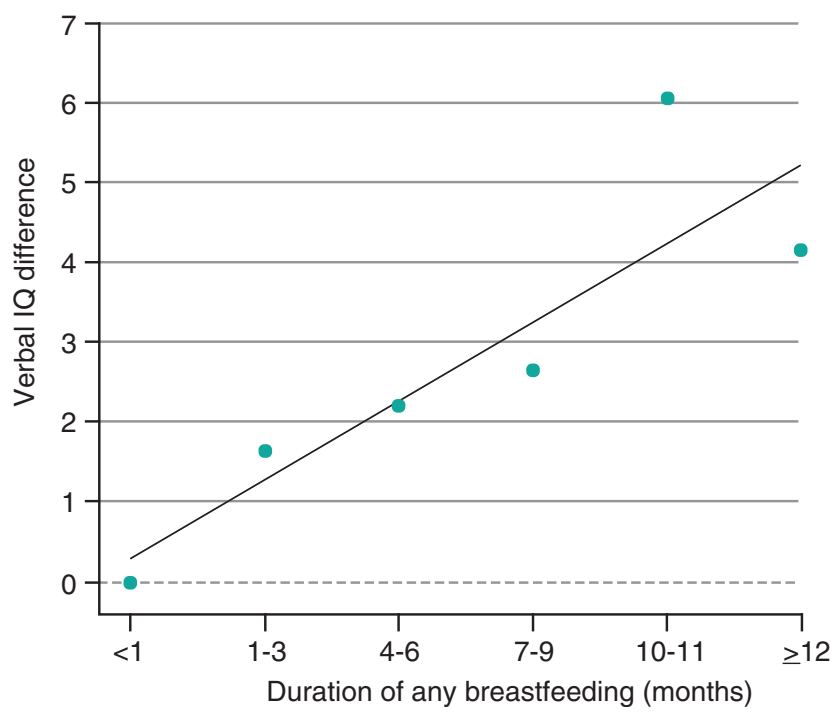

FIG. 2. Association of breastfeeding duration with verbal IQ at age 7 years. $^{8}$

milk in preterm infants has also been associated with longterm benefits in neurodevelopment. A large cohort study in extremely low birth weight infants $(<1,000$ grams; $N=1,035)$ found that breast milk consumption in the neonatal intensive care unit (NICU) resulted in dose-dependent increases in cognitive and motor development at 18 to 22 months that persisted through 30 months of age. ${ }^{14,15}$ However, another cohort study in premature infants born $\leq 33$ weeks gestation $(N=611)$ found no association between human milk intake and neurodevelopmental outcomes at 18 months. ${ }^{16}$ The inconsistent results reported in these and other published studies evaluating the potential benefits of human milk in preterm infants may be due to differences in study populations, older nutrition practices that did not account for the greater needs of preterm infants, and the assessment of infant and toddler outcomes, which are poorly predictive of later cognitive abilities.

A recent longitudinal cohort study included 180 breastfed children who were born at $<30$ weeks gestation or had a birth

Table 1. Predominant Maternal Milk Feeding AND SCHOOL-Age OUTCOMES

\begin{tabular}{lcr}
\hline & \multicolumn{2}{c}{$\begin{array}{c}\text { Increment in test score per } \\
\text { additional day } \text { on } \text { which infant } \\
\text { received }>50 \%\end{array}$} \\
\cline { 2 - 3 } & $\beta$ & $95 \%$ maternal milk \\
\hline IQ & $\mathbf{0 . 5}$ & $\mathbf{0 . 2}$ to $\mathbf{0 . 8}$ \\
Reading & 0.5 & -0.03 to 1.0 \\
Math & $\mathbf{0 . 5}$ & $\mathbf{0 . 1}$ to $\mathbf{0 . 9}$ \\
Attention & 0.02 & -0.1 to 0.1 \\
Working memory & $\mathbf{0 . 5}$ & $\mathbf{0 . 1}$ to $\mathbf{0 . 9}$ \\
Language & 0.4 & -0.1 to 1.0 \\
Visual perception & -0.03 & -0.1 to 0.09 \\
Motor function & $\mathbf{0 . 1}$ & $\mathbf{0 . 0 2}$ to $\mathbf{0 . 2}$ \\
\hline
\end{tabular}

Predominant maternal milk feeding and school-age outcomes. ${ }^{16}$

Estimates adjusted for age, sex, gestational age, NICU illness, and social risk. Boldface type indicates statistically significant result $(p<0.05)$.

NICU, neonatal intensive care unit.
Table 2. Maternal Milk Intake and Early Brain DEVELOPMENT

\begin{tabular}{lcc}
\hline & $\begin{array}{c}\text { Increment in brain volume }(c c) \\
\text { per additional day infant } \\
\text { received }>50 \% \text { maternal milk }\end{array}$ \\
\cline { 2 - 3 } & $\beta$ & $95 \%$ CI \\
\hline Intracranial volume & -0.42 & -1.84 to 0.99 \\
Total brain size & 0.00 & -1.21 to 1.21 \\
Total gray matter & -0.32 & -1.17 to 0.53 \\
Total white matter & 0.17 & -0.48 to 0.82 \\
Myelinated & -0.03 & -0.12 to 0.07 \\
Unmyelinated & 0.17 & -0.46 to 0.81 \\
Deep nuclear gray matter & $\mathbf{0 . 1 5}$ & $\mathbf{0 . 0 5}$ to $\mathbf{0 . 2 5}$ \\
Cerebellum & 0.03 & -0.07 to 0.12 \\
Hippocampus & 0.001 & -0.01 to 0.01 \\
\hline
\end{tabular}

Maternal milk intake and early brain development. ${ }^{16}$

Estimates adjusted for age, sex, gestational age, NICU illness, and social risk. Boldface type indicates statistically significant result $(p<0.05)$.

weight of $<1,250$ g. ${ }^{17}$ The number of days the infants received predominantly maternal milk (i.e., $>50 \%$ of total enteral intake) was recorded over the first 28 days of life. There was no association between breast milk intake and cognitive and motor development at 2 years of age. At 7 years of age, the Full Scale IQ was 0.5 points higher for each additional day the infant received $>50 \%$ maternal milk (Table 1 ). $\mathrm{Si}$ milar increases were seen in scores for reading, math, and working memory. An assessment of total and regional brain volumes at term-equivalent age showed an increase in deep nuclear gray matter (thalamus and basal ganglia) volume of $0.15 \mathrm{cc} /$ day for each additional day of breast milk $>50 \%$ of intake (Table 2). An association between average daily breast milk intake during the first 28 days and hippocampal volume $(0.02 \mathrm{cc}$ per $10 \mathrm{~mL} /[\mathrm{kg} \cdot$ day $]$ of breast milk; $95 \%$ confidence interval [0.004-0.03]) was also seen at term. No differences in brain volumes were detected at school age. Overall, the results from this study suggest that human milk may contribute to improved neurodevelopment assessed at school age. The increase in volumes of the thalamus, basal ganglia, and hippocampus observed at term may help shed light on potential mechanisms by which breast milk affects later neurodevelopmental outcomes.

Remaining questions to be addressed in future studies include characterizing the effects of donor human milk on early brain development and neurodevelopmental outcomes, identifying what components in human milk drive neurodevelopment, determining how to ensure adequate nutrient intake for preterm infants, and defining the mechanisms by which human milk/breastfeeding affects early brain development.

\section{References}

1. Smyser CD, Kidokoro H, Inder TE. Magnetic resonance imaging of the brain at term equivalent age in extremely premature neonates: To scan or not to scan? J Paediatr Child Health 2012;48:794-800.

2. Estes ML, McAllister AK. Maternal immune activation: Implications for neuropsychiatric disorders. Science 2016; 353:772-777. 
3. Andreas NJ, Kampmann B, Mehring Le-Doare K. Human breast milk: A review on its composition and bioactivity. Early Hum Dev 2015;91:629-635.

4. Lavelli M, Poli M. Early mother-infant interaction during breast- and bottle-feeding. Infant Behav Dev 1998;21:667-683.

5. Smith J, Ellwood M. Feeding patterns and emotional care in breastfed infants. Soc Indic Res 2011;101:227-231.

6. Kim P, Feldman R, Mayes LC, et al. Breastfeeding, brain activation to own infant cry, and maternal sensitivity. $J$ Child Psychol Psychiatry 2011;52:907-915.

7. Rahkonen P, Heinonen K, Pesonen AK, et al. Mother-child interaction is associated with neurocognitive outcome in extremely low gestational age children. Scand J Psychol 2014;55:311-318.

8. Belfort MB, Rifas-Shiman SL, Kleinman KP, et al. Infant feeding and childhood cognition at ages 3 and 7 years: Effects of breastfeeding duration and exclusivity. JAMA Pediatr 2013;167:836-844.

9. Deoni SC, Dean DC 3rd, Piryatinsky I, et al. Breastfeeding and early white matter development: A cross-sectional study. Neuroimage 2013;82:77-86.

10. Kramer MS. Breastfeeding and child cognitive development: New evidence from a large randomized trial. Arch Gen Psychiatry 2008;65:578-584.

11. Meinzen-Derr J, Poindexter B, Wrage L, et al. Role of human milk in extremely low birth weight infants' risk of necrotizing enterocolitis or death. J Perinatol 2009;29:57-62.

12. Furman L, Taylor G, Minich N, et al. The effect of maternal milk on neonatal morbidity of very low-birthweight infants. Arch Pediatr Adolesc Med 2003;157: 66-71.
13. Sisk PM, Lovelady CA, Dillard RG, et al. Early human milk feeding is associated with a lower risk of necrotizing enterocolitis in very low birth weight infants. $J$ Perinatol 2007;27:428-433.

14. Vohr BR, Poindexter BB, Dusick AM, et al. Beneficial effects of breast milk in the neonatal intensive care unit on the developmental outcome of extremely low birth weight infants at 18 months of age. Pediatrics 2006;118: e115-e123.

15. Vohr BR, Poindexter BB, Dusick AM, et al. Persistent beneficial effects of breast milk ingested in the neonatal intensive care unit on outcomes of extremely low birth weight infants at 30 months of age. Pediatrics 2007;120: e953-e959.

16. Jacobi-Polishook T, Collins CT, Sullivan TR, et al. Human milk intake in preterm infants and neurodevelopment at 18 months corrected age. Pediatr Res 2016;80:486-492.

17. Belfort MB, Anderson PJ, Nowak VA, et al. Breast milk feeding, brain development, and neurocognitive outcomes: A 7-year longitudinal study in infants born at less than 30 weeks' gestation. J Pediatr 2016;177:133-139.e1.

Address correspondence to: Mandy Brown Belfort, MD, MPH Department of Pediatric Newborn Medicine Brigham and Women's Hospital 75 Francis Street Boston, MA 02115

E-mail: mbelfort@bwh.harvard.edu 